\title{
Impactos socioemocionales, estrategias y retos docentes en el nivel medio superior durante el confinamiento por COVID-19
}

\section{Socio-Emotional Impacts, Strategies and Teaching Challenges at the High School Level During Confinement Due to COVID-19}

\begin{abstract}
Impactos socioemocionais, estratégias e desafios pedagógicos no ensino médio durante o confinamento por COVID-19
\end{abstract}

\author{
Herlinda Gervacio Jiménez \\ Universidad Autónoma de Guerrero, México \\ lindagj09@gmail.com \\ https://orcid.org/0000-0003-3037-9528 \\ Benjamín Castillo Elías \\ Universidad Autónoma de Guerrero, México \\ bcastilloelias@gmail.com \\ https://orcid.org/0000-0003-1487-5353
}

\section{Resumen}

El objetivo de la presente investigación fue identificar las problemáticas, experiencias y situaciones de emergencia en las que se encuentran inmersos los docentes del Colegio Nacional de Educación Profesional Técnica, México, a raíz del confinamiento ocasionado por la pandemia del coronavirus Covid-19, con la finalidad de generar datos e información que revele las condiciones y estrategias pedagógicas que han permitido a los docentes de este subsistema continuar con su labor docente. Se implementó la metodología cualitativa de investigación-acción, al igual que la observación participante y la recolección de información de historias de vida. Se seleccionó una muestra de 388 docentes. Los resultados permitieron identificar las dimensiones físicas, emocionales y cognitivas que se han visto afectadas. Los 

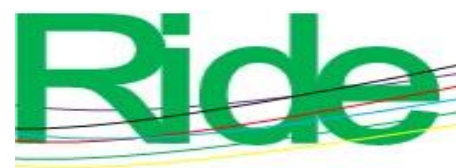

Revista Iberoamericana para la Investigación y el Desarrollo Educativo ISSN 2007 - 7467

docentes sufren de angustia, miedo, depresión e irritabilidad. Además, subrayaron la necesidad de contar con espacios físicos tranquilos para su bienestar y salud mental, y señalaron a la seguridad laboral como la principal preocupación, aquello que se interpone para alcanzar estabilidad y bienestar económico. Se concluye con el hecho de que los efectos de la pandemia actual no solo han sido emocionales y físicos, sino también socioeconómicos. Palabras clave: aislamiento escolar, COVID-19, estrés laboral, impactos socioemocionales, personal educativo, resiliencia docente.

\section{Abstract}

The objective of this research was to identify the problems, experiences and emergency situations in which the teachers of the National College of Technical Professional Education, Mexico, are immersed as a result of the confinement caused by the Covid-19 coronavirus pandemic, with the purpose of generating data and information that reveal the conditions and pedagogical strategies that have allowed the teachers of this subsystem to continue with their teaching work. The qualitative methodology of research-action was implemented, as well as participant observation and the collection of information from life stories. A sample of 388 teachers was selected. The results allowed to identify the physical, emotional and cognitive dimensions that have been affected. Teachers suffer from anxiety, fear, depression and irritability. In addition, they underlined the need to have quiet physical spaces for their wellbeing and mental health, and pointed to job security as the main concern. It concludes with the fact that the effects of the current pandemic have not only been emotional and physical, but also socioeconomic.

Keywords: education lockdown, COVID-19, occupational stress, socio-emotional impacts, educational personnel, teacher resilience. 


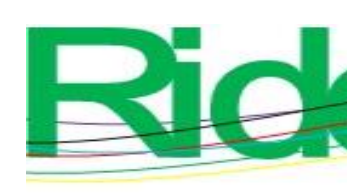

Revista Iberoamericana para la
Investigación y el Desarrollo Educativo
ISSN $2007-7467$

\section{Resumo}

O objetivo desta pesquisa foi identificar os problemas, vivências e situações emergenciais em que os docentes do Colégio Nacional de Educação Profissional Técnica, México, como resultado do confinamento causado pela pandemia de coronavírus Covid-19, com a finalidade de gerar dados e informações que revelam as condições e estratégias pedagógicas que têm permitido aos professores deste subsistema dar continuidade ao seu trabalho docente. Foi implementada a metodologia qualitativa de pesquisa-ação, observação participante e coleta de informações de histórias de vida. Uma amostra de 388 professores foi selecionada. Os resultados permitiram identificar as dimensões físicas, emocionais e cognitivas que foram afetadas. Os professores sofrem de ansiedade, medo, depressão e irritabilidade. Além disso, sublinharam a necessidade de espaços físicos tranquilos para o seu bem-estar e saúde mental, e apontaram a segurança do emprego como a principal preocupação, aquela que impede a estabilidade e o bem-estar económico. Conclui com o fato de que os efeitos da atual pandemia não foram apenas emocionais e físicos, mas também socioeconômicos.

Palavras-chave: bloqueio educacional, COVID-19, estresse ocupacional, impactos socioemocionais, pessoal educacional, resiliência de professores.

Fecha Recepción: Agosto $2021 \quad$ Fecha Aceptación: Febrero 2022

\section{Introducción}

La pandemia de la enfermedad por coronavirus de 2019 (Covid-19) ha transformado las distintas dimensiones de la vida humana. Al igual que en otras actividades laborales, la educación y la docencia han sufrido grandes transformaciones. La cuarentena impuesta a nivel global tuvo la finalidad de evitar la propagación del virus zoonótico que se transmite entre animales y humanos conocido como $S A R S-C o V-2$ y que provoca la Covid-19 (Chen, Liu y Guo, 2020). De acuerdo con los propios Chen et al. (2020), los coronavirus son patógenos que pueden infectar el sistema respiratorio, gastrointestinal, hepático y nervioso central del humano.

En este contexto de crisis mundial, los sistemas económicos, de salud y educativos se vieron y continúan siendo seriamente afectados. En este último, considerado como uno de los sectores más importantes para la sociedad, la comunidad educativa hizo frente a la emergencia sanitaria a través de plataformas virtuales u otros medios de comunicación, de tal manera que la educación de los estudiantes no se interrumpió, sino que continuó de manera remota. 


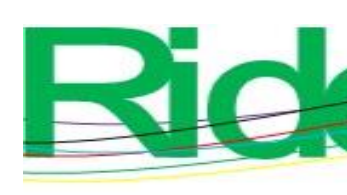

\section{Revista Iberoamericana para la Investigación y el Desarrollo Educativo ISSN 2007 - 7467}

Sin embargo, para los profesores no fue una labor sencilla: tuvieron que adaptarse rápidamente a una modalidad de enseñanza totalmente distinta a la que venían practicando, al menos para la mayoría de ellos, y a la par lidiar con los estragos de una pandemia global. Estudios como los de Garrick et al. (2014), Jensen, Sandoval, Knoll y González (2012) y Skaalvik y Shaalvik (2015) dieron cuenta sobre la existencia de altos índices de insatisfacción, estrés, agotamiento y depresión de docentes activos. De hecho, de acuerdo con Sanz, García, Rubio, Santed y Montoro (2002), la docencia es considerada como una profesión que presenta un alto riesgo de angustia psicológica: si se comparan con los de la población en general, registra los niveles más bajos de satisfacción laboral. Mientras que, en un estudio reciente, Alves, Lopes y Precioso (2020) encontraron que la pandemia ha reducido aún más la percepción de bienestar entre los docentes y ha acentuado la incertidumbre sobre su futuro profesional.

Lozano (2020) y Morales (2021) han documentado que el trabajo docente provoca estrés, incertidumbre, miedo, en suma, un impacto psicológico negativo, sobre todo en la población más vulnerable. Asimismo, la Organización de las Naciones Unidas para la Educación, la Ciencia y la Cultura [Unesco], en colaboración con el Instituto Internacional para la Educación Superior en América Latina y el Caribe [Iesalc] (2020), han confirmado que la pandemia por Covid-19 ha causado fuertes impactos psicológicos en la comunidad educativa: el cierre de los centros educativos, la necesidad del distanciamiento físico, la pérdida de seres queridos, del trabajo y el cambio de los métodos de aprendizaje tradicionales han generado estrés, presión y ansiedad, a docentes, estudiantes y sus familias.

Los impactos provocados por la actual pandemia han afectado significativamente la educación en todos sus procesos, tanto en el ámbito educativo como en el ámbito social y personal de toda la comunidad educativa (Gervacio y Castillo, 2021). Como se ha documentado, la educación a distancia ha tomado relevancia y se ha convertido en una alternativa para continuar los procesos académicos desde los hogares (Robinet y Pérez, 2020). Los docentes, a raíz de estos cambios, han tenido que reajustar su vida cotidiana para adaptarse a un cambio inesperado que generó efectos en términos de equilibrio socioemocional (Tacca y Tacca, 2019).

El proceso de adaptación de contenidos, uso de las distintas plataformas y la adaptación a las nuevas necesidades educativas emergentes requieren del uso de distintas competencias profesionales, así como de competencias docentes que permitan desarrollar el trabajo académico de manera eficaz. De esta manera, las competencias emocionales han sido 


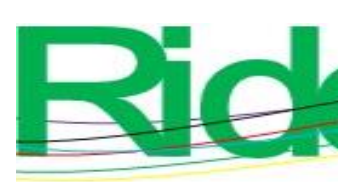

Revista Iberoamericana para la
Investigación y el Desarrollo Educativo
ISSN $2007-7467$

fundamentales para el desarrollo de conocimientos, habilidades, actitudes y valores necesarios para identificar, comprender, expresar y regular de forma apropiada los fenómenos emocionales que padece la sociedad en general y en particular el profesorado y sus estudiantes. De acuerdo con Bisquerra y Mateo (2019); Pérez y Filella (2019), entre las competencias emocionales están la conciencia emocional, la regulación emocional, la autonomía emocional, la competencia social, las competencias para la vida y el bienestar, las cuales son consideradas necesarias e importantes para poder enfrentar el reto que representa la educación en tiempos de pandemia.

La docencia es considerada como una profesión de alto sentido social. Sin embargo, también es una ocupación que presenta, en comparación con los de la población en general, los niveles más bajos de satisfacción laboral (Sanz et al., 2002). Y el traslado de la educación al plano virtual ha evidenciado todavía más los problemas de salud física y emocional que padece el profesorado. De acuerdo con López y Pérez (2020), la docencia actualmente es una amenaza a la salud y al bienestar de quienes la ejercen. Otros estudios han documentado que, si bien los docentes han estado siempre bajo constante presión, dicha presión se ha acentuado debido a los actuales acontecimientos provocados por la actual pandemia.

Al respecto, el Ministerio de Educación de Perú (1 de abril de 2020) parte del hecho de que el bienestar socioemocional afecta el qué y el cómo se aprende. Por tanto, las crisis ocasionan fuertes respuestas emocionales negativas como miedo, estrés, pánico, ansiedad, por lo que la construcción de las habilidades de aprendizaje socioemocional permite abordar situaciones estresantes con respuestas asertivas y con un pensamiento crítico.

Aunado a ello, el estrés y el miedo tienen un impacto negativo en la salud y en la capacidad de aprender; solo cuando el cerebro está socialmente conectado y emocionalmente seguro puede enfocarse en el contenido académico y participar correctamente en el aprendizaje (Unesco-Iesalc, 2020).

En esa misma línea, Aguaded y Almeida (2016) afirman que la forma en que cada persona responde a las adversidades de la vida y a las experiencias contribuye o afecta el desarrollo personal. Se trata de una competencia fundamental de todo profesional de la educación. De esta manera, para promover una salud emocional, se requiere articular de manera consciente las dimensiones de emoción, cognición y comportamiento, lo que permitirá perseverar en el logro de objetivos a pesar de las dificultades y ejercitará la tolerancia a la frustración. 


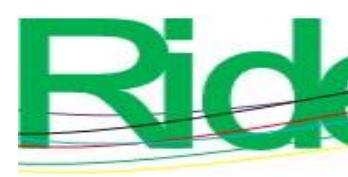

Revista Iberoamericana para la
Investigación y el Desarrollo Educativo
ISSN $2007-7467$

La Secretaría de Educación Pública [SEP] (2020) se planteó como objetivo contribuir al fortalecimiento de la resiliencia del sistema educativo con la finalidad de prevenir y atender situaciones de emergencia mediante asistencia técnica a las autoridades y funcionarios educativos, así como a través del fortalecimiento de las capacidades de los docentes. Esto por medio de la producción y difusión de espacios virtuales especializados y la oferta de una serie de herramientas enfocadas en temas relacionados al desempeño y desarrollo de las actividades docentes y el fortalecimiento de las habilidades socioemocionales.

Gervacio y Castillo (2020) han documentado que el Colegio Nacional de Educación Profesional Técnica (Conalep) del Nivel Medio Superior ha implementado estrategias metodológicas en todos sus planteles a nivel Nacional para dar seguimiento a la enseñanza y aprendizaje de forma virtual. Este seguimiento ha incluido el fortalecimiento de las habilidades socioemocionales de docentes de este subsistema en todos los planteles del país, de tal manera que estos cuenten con estrategias sobre el manejo de emociones, estrés y autorregulación en el contexto de la pandemia y el confinamiento.

Asimismo, Gervacio y Castillo (2021) afirman que el estrés al que está sometida actualmente la comunidad educativa ha afectado principalmente a los estudiantes y docentes debido a diversos factores relacionados con las clases virtuales, tales como escasa conectividad, el manejo de las herramientas tecnologías y plataformas virtuales, así como una crítica situación económica, vulnerabilidad y desigualdad social que se han evidenciado por la actual pandemia.

En este marco, el Conalep implementó a nivel Nacional estrategias para lograr la estabilidad emocional de los miembros de la comunidad educativa de este subsistema. A través de un programa llamado Preparándonos para una nueva normalidad, promovió herramientas y estrategias con las cuales se pretende la estabilidad emocional del docente. Este programa incluye cursos masivos abiertos en línea (MOOC, por sus siglas en inglés) como estrategia para el fortalecimiento de las habilidades socioemocionales del docente, así como el diseño de estrategias para afrontar aspectos socioemocionales ante la pandemia.

El objetivo de la presente investigación fue identificar las dimensiones socioemocionales, problemáticas, experiencias y situaciones de emergencia en las que se encuentran inmersos los docentes del Conalep ante el confinamiento ocasionado por la pandemia del SARS-CoV-2, con la finalidad de generar datos e información que revelen las condiciones y estrategias pedagógicas que han permitido a los docentes de este subsistema continuar con su labor docente. 


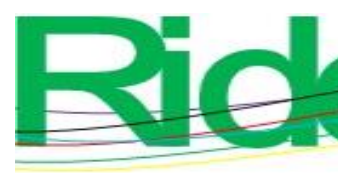

Revista Iberoamericana para la
Investigación y el Desarrollo Educativo
ISSN $2007-7467$

\section{Hipótesis de investigación}

La interrupción de las rutinas, la reducción de las interacciones sociales y la privación de los métodos de enseñanza-aprendizaje tradicionales provocados por el confinamiento de la pandemia Covid-19, han dado como resultado una mayor presión, estrés y ansiedad en el profesorado, lo que ha afectado significativamente su estado emocional y rendimiento laboral.

\section{Metodología}

La presente investigación surge en un marco de incertidumbre ante el inminente regreso a las clases presenciales. Como estrategia para estabilizar las dimensiones socioemocionales, el Conalep implementó MOOC para coadyuvar en la estabilidad emocional de los miembros de la comunidad educativa de este subsistema, parte del programa "Preparándonos para una nueva normalidad".

Se contó con la participación de 13356 docentes del sistema Conalep de distintos planteles estatales y regionales de la república mexicana. De este total de participantes, siguiendo a Sierra (2001) y Pértigas y Pita (2002), se eligió un tamaño de muestra representativa de 388 docentes. Cabe señalar que para llegar a esta cifra se utilizó la siguiente fórmula:

$$
n=\frac{4 * \mathrm{~N} * \mathrm{p} * \mathrm{q}}{E^{2}(\mathrm{~N}-1)+4 * \mathrm{p} * \mathrm{q}}
$$

Donde:

- $\quad n$ : tamaño de la muestra;

- $\quad \quad \quad \quad$ : tamaño de la población;

- $\quad p$ : probabilidad de éxito $=0.5$;

- $q$ : probabilidad de fracaso $=0.5$;

- $\quad E^{2}$ : error seleccionado por el investigador $=0.05, \mathrm{y}$

- 4 : constante.

Esta investigación se articuló a través de un planteamiento metodológico cualitativo basado en la investigación-acción (Rekalde, Vizcarra y Macazaga, 2014). Dentro de ésta, el diálogo sobre las "experiencias vivenciales" ha constituido un aspecto clave en la construcción de nuevos conocimientos. Como señala Pérez (2008), uno de los rasgos de esta metodología es la unión de teoría y práctica, la cual abre la puerta a una investigación más 

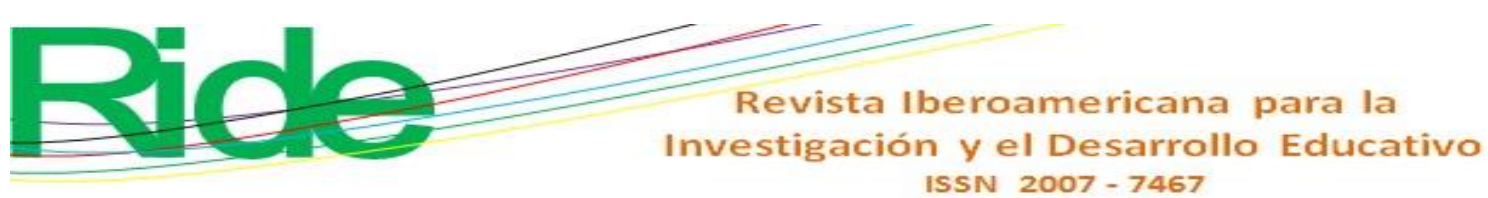

abierta, flexible, participativa, asequible a cualquier profesional y, sobre todo, comprometida con la resolución de problemas prácticos (Rekalde et al., 2011).

Igualmente, se retomó la técnica de Gervacio y Castillo (2020), quienes utilizaron la claridad y la precisión como unidades de análisis para sistematizar experiencias educativas, lo cual se replicó aquí para sistematizar precisamente las experiencias vivenciales personales de los docentes bajo estudio. Por supuesto, se privilegió el diálogo a través de los talleres, foros y chats virtuales tipo MOOC, que fueron impartidos por docentes expertas en el tema, quienes estimularon la acción dialógica mediante la técnica expositiva, gracias a lo cual se obtuvo información y datos relevantes sobre los impactos socioemocionales provocados por la pandemia de la Covid-19. Estos fueron clasificados en cuatro dimensiones socioemocionales, como se muestra en la figura 1.

Figura 1. Clasificación de las dimensiones socioemocionales
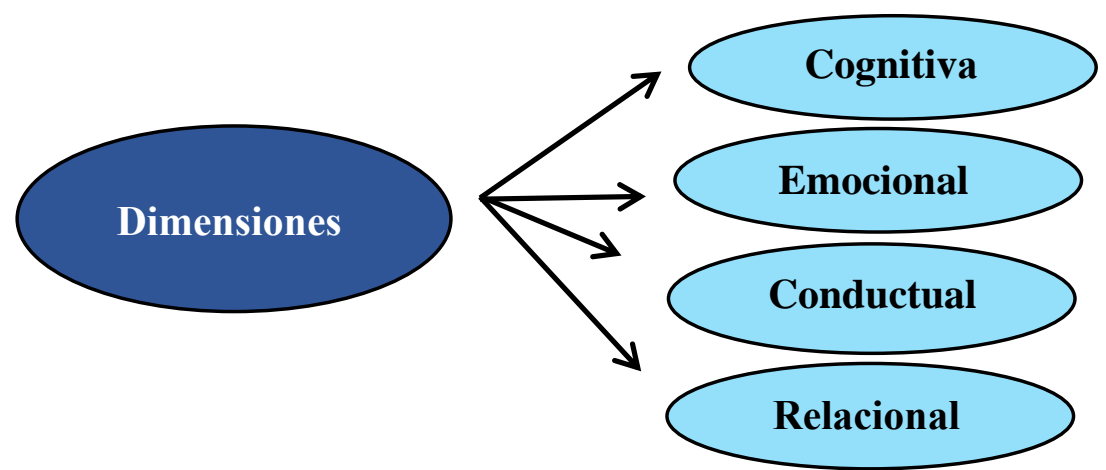

Fuente: Elaboración propia con datos del Centro de Perfeccionamiento, Experimentación e Investigaciones Pedagógicas [Cpeip] (2020)

El análisis de las experiencias narradas y registradas se clasificaron con base en la claridad y precisión. A partir de éstas, se hicieron inferencias con la técnica de análisis de contenido y fueron agrupadas en descriptiva, objetiva y sistemática (Fernández, 2002; Hernández y Mendoza, 2018; Unesco, 2016). Dentro de este planteamiento, la comunicación y el diálogo constituyó un aspecto clave para la construcción de conocimiento (Freire, 2014; Habermas, 2018). Se utilizó el software de apoyo ATLAS.ti v8 para el análisis cualitativo de contenidos (Varguillas, 2006), donde se hicieron inferencias válidas y confiables de datos que muestran el contexto que están viviendo los docentes bajo estudio (Hernández, Fernández y Baptista, 2014). 

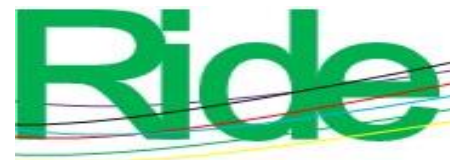

Revista Iberoamericana para la Investigación y el Desarrollo Educativo

ISSN 2007 - 7467

\section{Resultados}

Los resultados se presentan en dos bloques. El primero corresponde a la estructura metodológica con la que se impartieron los talleres virtuales denominados $M O O C$, que permitieron la realización de esta investigación. El segundo bloque corresponde a los resultados obtenidos propiamente de los talleres.

De esta manera, se describe a continuación el contexto en el cual se desarrollaron los talleres virtuales vivenciales "Resignificarme en situaciones de emergencia". Cabe precisar que fueron realizados en el marco de un posible retorno a las clases presenciales e impartidos por especialistas en logoterapia del Instituto Nacional de Psiquiatría. Así, se contó con el apoyo de 15 expertas psicólogas y tanatólogas que estuvieron atendiendo a los docentes a través de foros virtuales "Experiencias vivenciales", donde se canalizaron preguntas, dudas y casos especiales; impartiéndose cinco talleres con un total de 20 horas.

El enfoque metodológico, pedagógico que se utilizó para los talleres, así como sus objetivos, se detallan en la tabla 1 . 


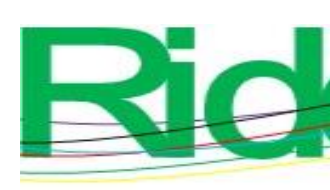

Revista Iberoamericana para la Investigación y el Desarrollo Educativo ISSN 2007 - 7467

Tabla 1. Taller virtual: "Resignificarme en situaciones de emergencia"

\begin{tabular}{|c|c|}
\hline \multicolumn{2}{|r|}{ Dirigidos a docentes del sistema Conalep } \\
\hline Enfoque metodológico & $\begin{array}{l}\text { La metodología empleada para el desarrollo del MOOC estuvo } \\
\text { basado en el aprendizaje vivencial, en donde se buscó } \\
\text { conducir al participante al autoconocimiento y } \\
\text { autorregulación de sus emociones a través de herramientas y } \\
\text { consejos prácticos que le permitan avanzar y adaptarse a la } \\
\text { realidad pese a las circunstancias que se le presenten. } \\
\text { Para la realización de los talleres se contó con la participación } \\
\text { de especialistas en los temas, con el fin de promover acciones } \\
\text { que lleven a los participantes a tener resultados de mayor } \\
\text { bienestar y satisfacción personal y profesional. } \\
\text { Considerando la importancia del tema, se desarrollaron } \\
\text { algunos recursos, emocionales y prácticos, para que los } \\
\text { participantes cuenten con las herramientas necesarias para un } \\
\text { regreso seguro. }\end{array}$ \\
\hline Enfoque pedagógico & Autoaprendizaje y aprendizaje social \\
\hline Objetivo & $\begin{array}{l}\text { Dialogar con los docentes del sistema Conalep, conocer cómo } \\
\text { están viviendo la pandemia, para tratar de fortalecer su lado } \\
\text { humano, mejorar los estados emocionales, proporcionarles las } \\
\text { herramientas y elementos que les permita cumplir mejor con } \\
\text { su función e integrarlos a sus actividades docentes en mejores } \\
\text { condiciones, de tal manera que se genere en el interior de los } \\
\text { planteles un ambiente que supere el miedo, el dolor, la } \\
\text { incertidumbre en que actualmente se vive. }\end{array}$ \\
\hline $\begin{array}{l}\text { Apertura de curso para } \\
\text { docentes }\end{array}$ & Un primer acercamiento y reconocimiento de la plataforma. \\
\hline Sesiones en vivo & $\begin{array}{l}\text { A lo largo de estos días se trabajó de la mano de especialistas, } \\
\text { quienes identificaron y reconocieron las emociones, así como } \\
\text { aquello en lo que necesitan trabajar a través de experiencias } \\
\text { vivenciales, a fin de estar preparados para el regreso a las } \\
\text { instalaciones de trabajo. } \\
\text { Estas experiencias ofrecieron algunos recursos emocionales y } \\
\text { prácticos para acompañar al docente en el regreso a la nueva } \\
\text { normalidad y a su bienestar emocional para una mejor } \\
\text { interacción con su comunidad. } \\
\text { Se revisaron algunos aspectos teóricos como el manejo de } \\
\text { sentimientos, la relación entre la satisfacción de las } \\
\text { necesidades personales, la resiliencia y el sentido de vida. }\end{array}$ \\
\hline Recursos de apoyo & $\begin{array}{l}\text { Los recursos de apoyo permitieron abrir espacios respetuosos } \\
\text { para que, en caso de que los docentes lo necesitaran, } \\
\text { expresaran sus propias experiencias y los sentimientos } \\
\text { derivados de ellas durante este periodo de confinamiento y } \\
\text { contingencia sanitaria. }\end{array}$ \\
\hline
\end{tabular}




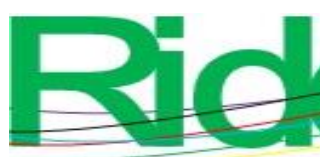

Revista Iberoamericana para la Investigación y el Desarrollo Educativo ISSN $2007-7467$

\section{Duración} Sesiones en vivo. 20 horas totales de los talleres

Fuente: Elaboración propia

En la tabla 2 se muestra un concentrado sobre las actividades que se desarrollaron con los docentes bajo estudio en los talleres virtuales. Asimismo, se puede observar cada una de las experiencias. Los principales objetivos fueron los siguientes:

1) Analizar el impacto de la Covid-19 mediante el relato de una experiencia personal con el fin de promover la corresponsabilidad ante la pandemia.

2) Desarrollar la capacidad de empatía, mediante la exposición de una situación adversa, con el fin de reconocer sus sentimientos y facilitar la empatía con otras personas.

3) Reflexionar sobre sus sentimientos y pensamientos en este tiempo de confinamiento para relacionarse con el otro.

4) Promover la utilización de los recursos resilientes y el descubrimiento y construcción del sentido de la vida para facilitar las experiencias de la nueva realidad.

5) Identificar acciones para la promoción de la salud emocional, propia y de los estudiantes, y reconocer los efectos causados por la pandemia. 
Tabla 2. Estructura del taller virtual: "Resignificarme en situaciones de emergencia"

\begin{tabular}{|c|l|}
\hline \multicolumn{2}{|c|}{ Dirigido a docentes del Conalep } \\
\hline Experiencia 1 & Vivencia personal durante la contingencia sanitaria y el confinamiento. \\
\hline Objetivo & $\begin{array}{l}\text { Analizar el impacto de la Covid-19 mediante el relato de una experiencia } \\
\text { personal con el fin de promover la corresponsabilidad ante la pandemia. }\end{array}$ \\
\hline Experiencia 2 & Mis sentimientos el confinamiento y la contingencia. \\
\hline Objetivo & $\begin{array}{l}\text { Desarrollar la capacidad de empatía, mediante la exposición de una } \\
\text { situación adversa, con el fin de reconocer mis sentimientos y facilitar la } \\
\text { empatía con las otras personas. }\end{array}$ \\
\hline Experiencia 3 & Relación entre mis necesidades satisfechas y mis sentimientos. \\
\hline Objetivo & $\begin{array}{l}\text { Reflexionar sobre nuestros sentimientos y pensamientos en este tiempo de } \\
\text { confinamiento para relacionarnos con el otro. }\end{array}$ \\
\hline Experiencia 4 & Vivir mi nueva realidad: resiliencia y sentido de vida. \\
\hline Objetivo & $\begin{array}{l}\text { Promover la utilización de recursos resilientes y el descubrimiento y } \\
\text { construcción del sentido de la vida para facilitar las experiencias de } \\
\text { nuestra nueva realidad. }\end{array}$ \\
\hline Experiencia 5 & Estrategias para promover con los estudiantes la salud emocional. \\
\hline Objetivo & $\begin{array}{l}\text { Identificar acciones para la promoción de la salud emocional, propia y de } \\
\text { los alumnos, reconociendo los efectos causados por la pandemia. }\end{array}$ \\
\hline
\end{tabular}

Fuente: Elaboración propia

El análisis que a continuación sigue se presenta por temáticas de cada taller. Así, enseguida se presentan los resultados correspondientes al taller número uno, "Vivencia personal durante la contingencia sanitaria y el confinamiento", cuyo objetivo fue analizar el impacto de la Covid-19 mediante el "relato de una experiencia personal" con el fin de promover la corresponsabilidad ante la pandemia.

En este primer taller los temas de discusión, así como las preguntas de reflexión, giran en torno a los sentimientos que han experimentado los docentes por la contingencia y la Covid-19, que actualmente tiene en cuarentena al sistema educativo y a la población en general.

Ha sido de mucho interés conocer cómo este periodo de tiempo ha hecho aflorar distintos sentimientos y emociones y las coincidencias entre los diversos componentes de la comunidad educativa.

En este taller, se consideraron las preguntas de reflexión: “¿Qué sentimientos han experimentado al conocer historias de vida sobre la Covid-19? y “ ¿Tienen alguna relación con tu propia experiencia ante la pandemia y el confinamiento?, ¿Cuál?’. 


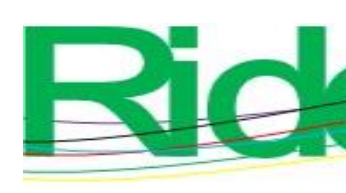

Revista Iberoamericana para la
Investigación y el Desarrollo Educativo
ISSN $2007-7467$

A partir de estas preguntas de reflexión, los docentes participantes tuvieron la oportunidad de expresar y exponer sus propias experiencias. Así, expresaron los sentimientos que han experimentado al conocer sobre el sufrimiento que están sintiendo familiares, amigos, estudiantes y ellos mismos; expresaron su preocupación, sus miedos, su enojo y sus sensaciones ante la evidente problemática que se está viviendo a nivel global; expresaron cómo la Covid-19 ha cambiado drásticamente sus rutinas de vida; expusieron que esta experiencia ha sido traumatizante y sus impactos han sido muy fuertes en todos los aspectos, tanto emocionales como económicos. Sin embargo, comentaron tener fe en que esta tragedia pasará y que les servirá como experiencia para modificar aspectos en su vida personal y profesional.

Este fragmento expone las inquietudes y comentarios sobre las preguntas de reflexión:

Este confinamiento nos ha tenido preocupados, angustiados y estresados debido a que desconocemos cómo ayudar a nuestra familia, nuestros amigos, nuestros estudiantes y a nosotros mismos. Hemos perdido familiares, compañeros maestros, vecinos y conocidos. Existe mucho miedo por el posible contagio. Tenemos familiares y conocidos enfermos, lo que nos tiene nerviosos y estresados. Existe incertidumbre por no saber qué pasará mañana.

Tenemos compañeros maestros y familiares de nuestros estudiantes que están en problemas de salud por este virus, las consecuencias y problemas han sido incalculables a nivel personal y económico. Existe alto grado de estrés, no solo por cuestiones de salud, sino también por el incremento de trabajo en casa, por los diversos cursos que nos están impartiendo para el uso de las plataformas virtuales; hay incertidumbre por conocer las condiciones de un posible regreso a las clases presenciales. Estamos angustiados por el cambio de rutina, tenemos nuevas actividades, hemos modificado horarios de trabajo y de sueño, estamos padeciendo de insomnio, nos sentimos depresivos, enojados, hay muchas cosas que no sé cómo reaccionar (...). Hemos trasladado el salón de clase a casa, hemos experimentado cambios físicos y emocionales en nuestras rutinas, en la convivencia con nuestras familias. 

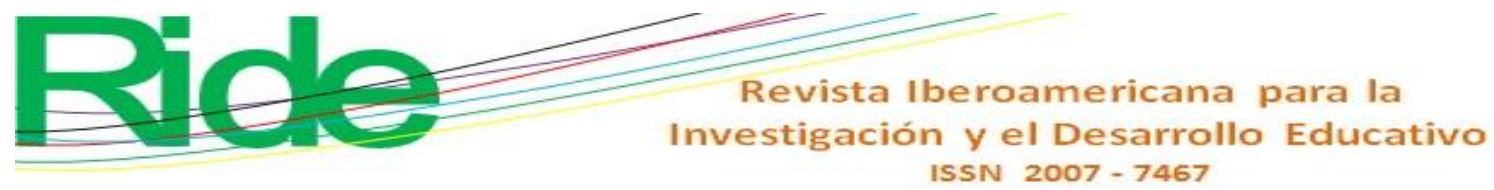

De acuerdo con la figura 2, la preocupación, angustia, miedo, estrés e irritabilidad son las principales percepciones cognitivas y conductuales que han expresado sentir los docentes durante el confinamiento.

Figura 2. Categorización de los sentimientos con la emergencia sanitaria

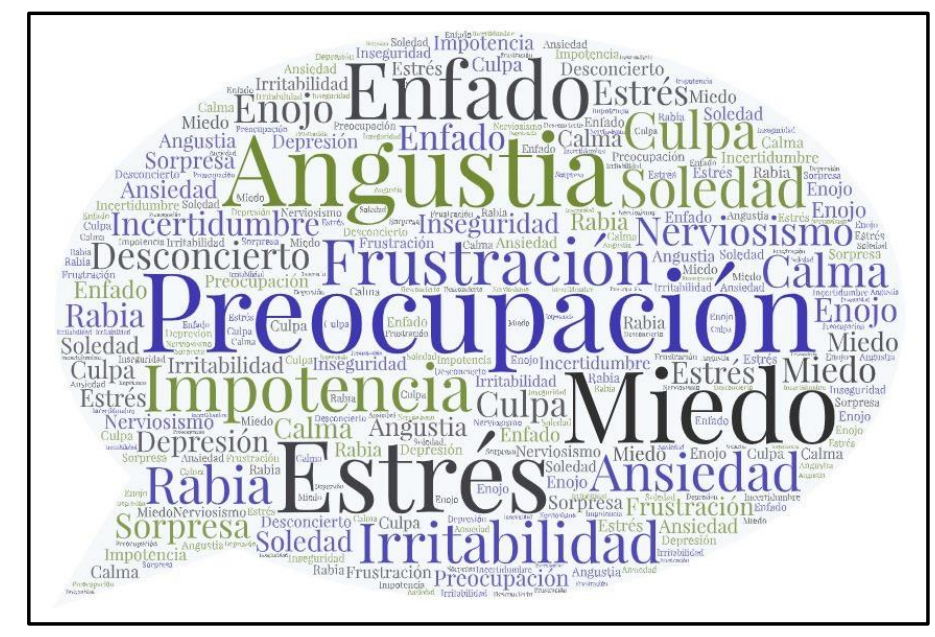

Fuente: Elaboración propia con software ATLAS. ti

En el segundo taller, "Mis sentimientos el confinamiento y la contingencia", tuvo como objetivo desarrollar la capacidad de empatía mediante la exposición de una situación adversa con el fin de reconocer los sentimientos y facilitar la empatía con otras personas.

En este taller, los docentes realizaron actividades lúdicas que les permitieron poner "color" a sus sentimientos, hablar sobre el sentido de vida y su trascendencia, así como reflexionar sobre los motivos y estrategias implementadas por los mismos para mantenerse "vivos y cuerdos" durante el confinamiento.

A partir de las siguientes preguntas de reflexión: "¿Qué emociones te conectan con la emergencia sanitaria?” y “¿Qué piensas sobre las medidas de seguridad adoptadas y la despersonalización de los afectos ante el confinamiento?”, se abrió el diálogo.

Los docentes expresaron su sentir, reflexionaron sobre sus vivencias personales, hablaron sobre sus propias experiencias vividas durante la pandemia y el confinamiento. Y confirmaron que existe temor y angustia por el presente y el porvenir de sus familias y de ellos mismos. El temor de infectarse por el virus les da una sensación de estar expuestos a un peligro real, lo que les ha permitido reflexionar sobre su propia existencia. 


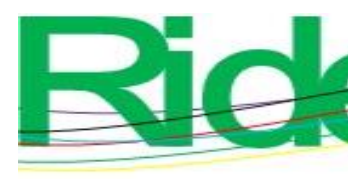

Revista Iberoamericana para la
Investigación y el Desarrollo Educativo
ISSN $2007-7467$

Mencionaron sentirse angustiados por no estar en contacto directo con sus familiares cercanos, nostalgia por sus propios estudiantes, ya que no les ha sido posible tener contacto personal, tal y como lo era antes de la pandemia. Expresaron sentirse depresivos por la falta de convivencia con la familia y amigos.

También afirmaron que, de alguna manera, han tenido ciertas enfermedades provocadas por el confinamiento: descuido en la alimentación, mal dormir, lo que les ha provocado insomnio. Respecto a las medidas de seguridad impuestas por las autoridades y la despersonalización de los efectos, los docentes aseguraron que existen medidas restrictivas pero el público en general no ha acatado las medidas como debería hacerlo, lo que ha provocado un incremento de infectados.

A continuación, se presenta un fragmento de los acontecimientos mencionados por los docentes bajo estudio:

La incertidumbre por no saber qué va a pasar con nuestra familia y con nosotros mismos, con nuestra salud, nos ha permitido hacer una reflexión sobre el proceso de nuestra vida y nuestra existencia; saber que está en riesgo la vida de nuestros familiares y de nosotros mismos nos ha provocado inestabilidad e incertidumbre emocional. Por otro lado, existen necesidades económicas: en caso de enfermedad o contagio, no contamos con recursos económicos para solventar los gastos médicos. Estamos experimentando temor y miedo ante este virus amenazante y desconocido. La irresponsabilidad de algunas personas que no acatan las recomendaciones sanitarias y en consecuencia no rompen la cadena de contagios; la situación de pánico que se vive a nuestro alrededor nos ha traído estrés; el aislamiento de nuestra familia y nuestros padres ha sido frustrante; el agobio de las actividades laborales, y las actividades de casa nos mantiene constantemente estresados. Sin embargo, debemos mantenernos firmes, responsables, congruentes y seguir adelante en espera de mejores tiempos, con la confianza de que saldremos adelante.

En cuanto a la responsabilidad e importancia de la salud emocional, los docentes afirmaron que el amor a la vida, el amor a su familia y la responsabilidad por su trabajo les ha permitido seguir adelante; aseguraron que mantenerse estables emocionalmente no ha sido fácil, han tenido que recurrir a distintas actividades como el ejercicio físico, la meditación o rezar, esto les ha permitido mantener la salud emocional relativamente estable. Otros más comentaron que las actividades manuales, cursos sobre diferentes temáticas, han sido de gran 

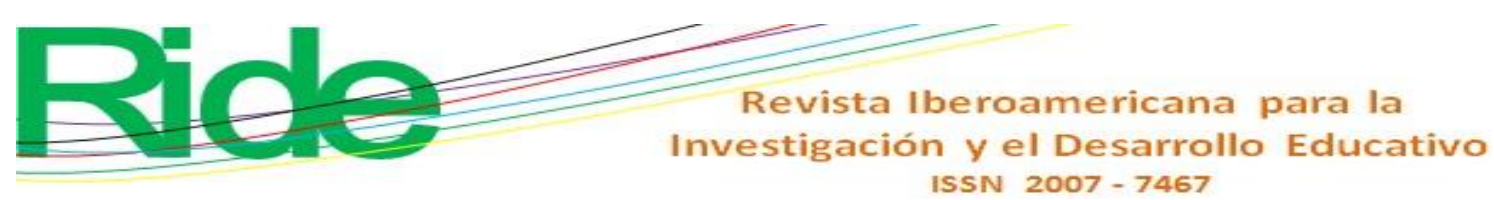

apoyo a los propios docentes y sus familias. Algunos otros se les ha dificultado mantenerse en equilibrio debido a las diferentes situaciones por las que están pasando, tal como no tener suficiente espacio en casa para sus actividades laborales, espacios para los hijos y la familia.

Las emociones de incertidumbre, depresión, miedo, estrés y angustia son las más sobresalientes como se muestra en la figura 3.

Figura 3. Categorización de la conexión de emociones con la emergencia sanitaria

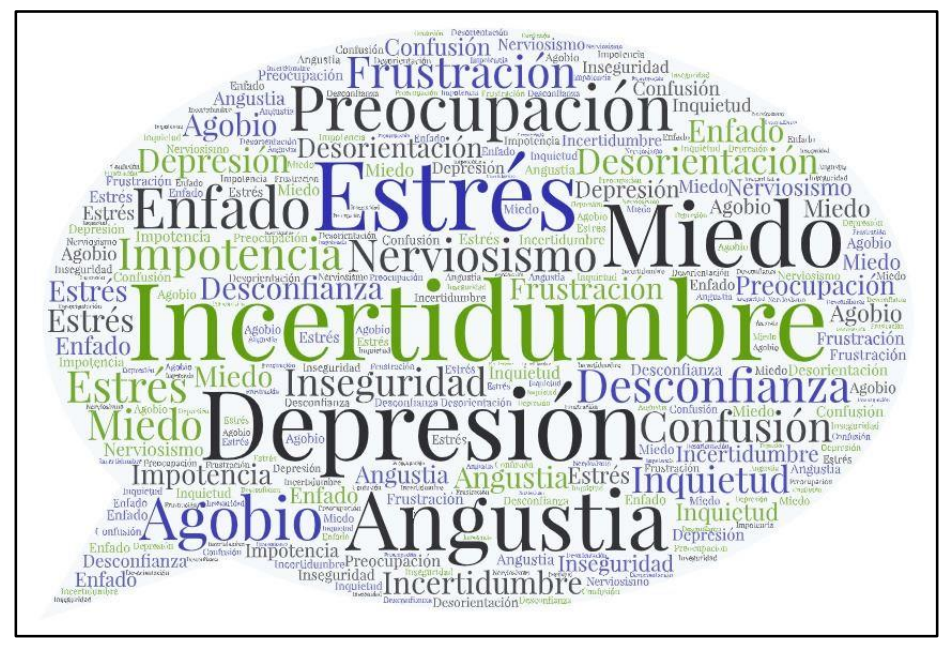

Fuente: Elaboración propia con software ATLAS. ti

En el tercer taller, "Relación entre mis necesidades satisfechas y mis sentimientos", cuyo objetivo fue la reflexión sobre los sentimientos y pensamientos en tiempo de confinamiento y la relación con otros, se plantearon las siguientes preguntas de reflexión: “¿Qué necesidades y sentimientos has contenido en este tiempo de confinamiento?” y “QQué parte de esta experiencia te hace sentir más humano y cercano a las necesidades tuyas y de los otros?".

En cuanto a las necesidades, los docentes comentaron que dentro de sus necesidades emergentes está la de un espacio, tanto físico como espacio personal, un espacio para sí mismos. Ha sido difícil, expresaron, tener un espacio físico en casa para acondicionarlo como estudio u oficina permanente que les permita realizar sus actividades laborales de forma cómoda y agradable, un espacio físico para sí mismos y los hijos o familiares que también realizan sus actividades escolares o laborales en casa debido a la pandemia, actividades que se han estado realizando desde el hogar.

Por lo tanto, han tenido que compartir todos los espacios en casa, lo que ha complicado la convivencia y el bienestar físico y emocional de la familia en general. Enfatizaron en la importancia de tener un espacio personal para la meditación, la reflexión o 


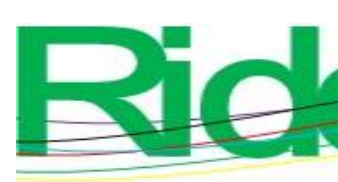

\section{Revista Iberoamericana para la Investigación y el Desarrollo Educativo ISSN 2007 - 7467}

el descanso, un espacio para sí mismos o simplemente para relajar la mente. E insistieron sobre la importancia de contar con tiempo y espacio para sí mismos ya que esto les permitiría una armonía física y mental, tan necesaria en tiempos complicados y cambiantes.

Lamentablemente, algunos docentes dijeron que donde viven ha sido más complicada la convivencia debido a que los espacios son reducidos, pero también aceptaron que se ha fortalecido el amor, la tolerancia y motivación entre la familia para seguir adelante y mantenerse unidos y a salvo.

Otra necesidad que han considerado de vital importancia para su bienestar es la de la seguridad laboral. Los docentes de este subsistema comentaron que en algunos de los planteles en los que laboran se debe renovar su contrato laboral cada semestre; además, se trabaja por horas, lo que los orilla a buscar otra fuente de ingreso, pues el tope de horas solo son 20 y, en consecuencia, el salario es muy bajo e inferior al de otros subsistemas educativos.

Se observó cómo los docentes reconocen la necesidad de espacios físicos tranquilos, algo fundamental para su bienestar y salud mental. Por otro lado, la seguridad laboral es la principal necesidad para su tranquilidad y para satisfacer sus necesidades básicas; contar con un salario decoroso que apoye ciertamente a la economía familiar (figura 4). Esta situación de inseguridad laboral es otro motivo de frustración, angustia y enojo.

Figura 4. Categorización de las necesidades y sentimientos con la emergencia sanitaria

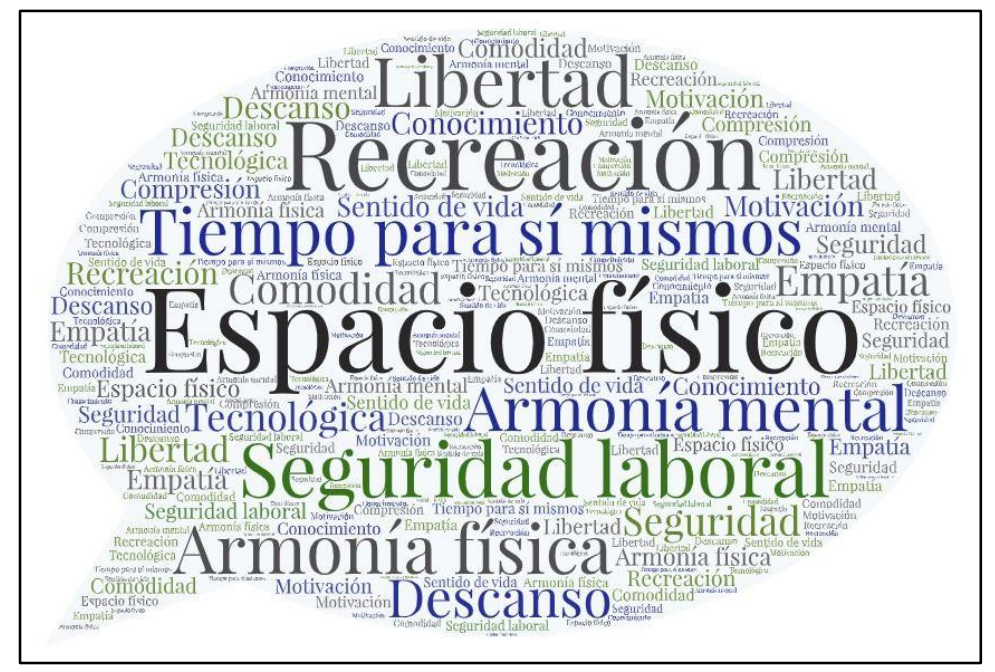

Fuente: Elaboración propia con software ATLAS. ti

Para el cuarto taller, "Vivir mi nueva realidad: resiliencia y sentido de vida", el objetivo fue promover la utilización de los recursos resilientes y descubrimiento y construcción del sentido de la vida para facilitar las experiencias de nuestra nueva realidad. 


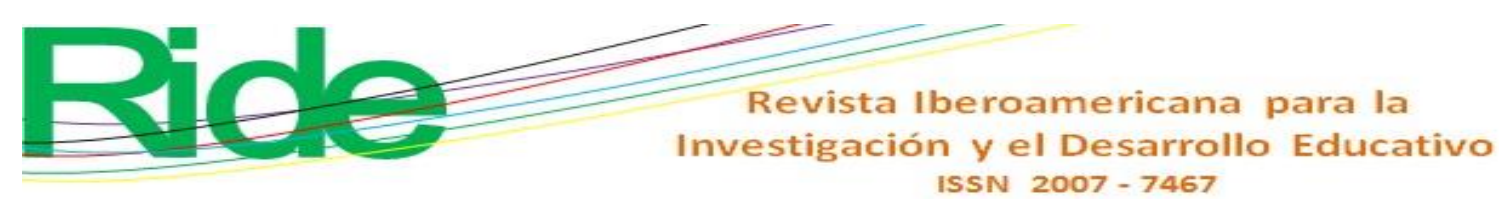

Se formularon las siguientes preguntas de reflexión: “¿Qué habilidades socioemocionales y académicas requiero para vivir en la nueva normalidad?” “ “ ¿Con cuál cuento para el regreso seguro?".

Las respuestas a estas interrogantes se dividieron en habilidades socioemocionales y académicas. Dentro de las principales habilidades socioemocionales que han considerado necesarias y fundamentales y que les ha permitido continuar y seguir adelante, ha sido la resiliencia, esta habilidad socioemocional de acuerdo a lo mencionado por algunos docentes, les ha permitido resistir al dolor por la pérdida de familiares, amigos o vecinos, les ha permitido ser fuertes ante el sufrimiento por alguna enfermedad, la resiliencia les ha permitido adaptarse y hacerle frente a la situación adversa provocada por la actual pandemia del coronavirus; los docentes coincidieron que ha sido necesario desarrollar habilidades socioemocionales que les permita seguir adelante con su vida y su trabajo, superando obstáculos y resolviéndolos de manera satisfactoria.

Los docentes afirmaron que han desarrollado empatía con sus estudiantes. Aún más, la consideran una habilidad social imprescindible para fomentar un clima agradable de relación docente-estudiante. Señalaron que la empatía les ha facilitado la comunicación y resolución de conflictos entre grupos y equipos de trabajo.

Por otro lado, dentro de las habilidades docentes, el trabajo colaborativo y en equipo ha sido considerado como una habilidad social fundamental para integrar el proyecto educativo que tienen en común. De acuerdo con el profesorado, son necesarias todas las habilidades personales y profesionales para llevar a buen término todas las actividades educativas, lo que les ha dado fructíferos resultados con los estudiantes.

Otra habilidad que los propios docentes han desarrollado, según sus comentarios, es la iniciativa personal, que les ha permitido emprender cosas nuevas potencializando sus habilidades docentes. En el contexto que actualmente viven, consideraron que sin esta habilidad no podrían haber continuado aprendiendo las nuevas metodologías y estrategias virtuales para innovar en su actividad laboral como docentes. En consecuencia, dijeron que han tenido que tomar la iniciativa para seguir aprendiendo de forma autónoma y para seguir desarrollando habilidades digitales tan necesarias en su actual desempeño como docentes.

En la figura 5 se muestra cómo los docentes explicaron que, a partir de la automotivación, han fortalecido su propia resiliencia; también están conscientes de que es necesario seguir construyendo y promoviendo esta cualidad con los estudiantes. 

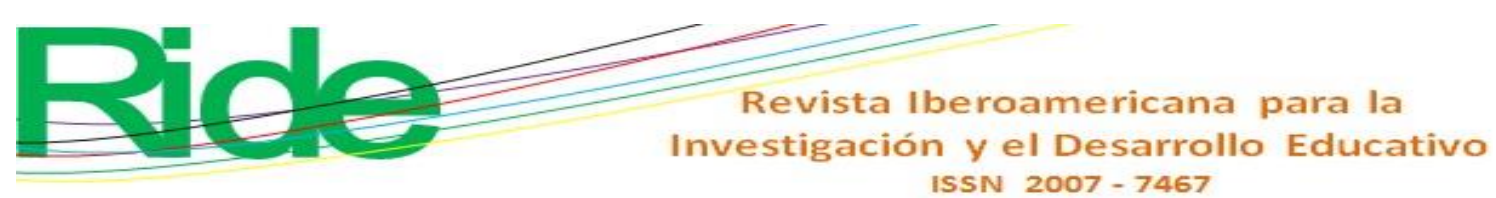

Figura 5. Categorización de habilidades socioemocionales y profesionales

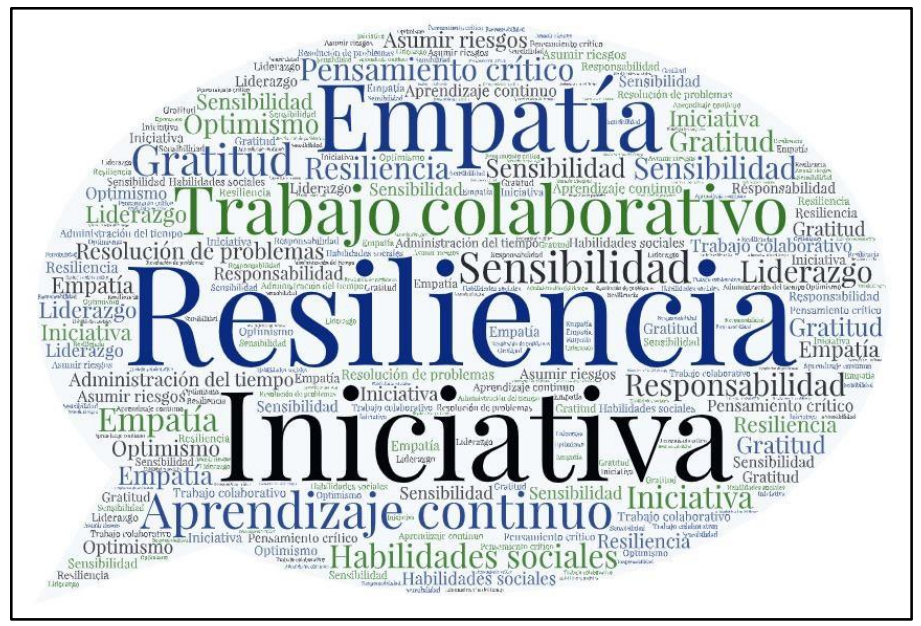

Fuente: Elaboración propia con software ATLAS. ti

Con respecto a las habilidades académicas y educativas, los docentes consideraron la habilidad digital indispensable para vivir y trabajar ante la evidente pandemia global, el conocimiento tecnológico, la creatividad y la capacidad de comunicar de forma correcta el mensaje que se desea que los demás entiendan y atiendan.

Ver la nueva realidad con un pensamiento crítico es una habilidad que los docentes consideran importante desarrollar tanto entre ellos mismos como con los estudiantes. El profesorado mencionó que es necesario pensar de manera crítica y fomentar esta habilidad en los estudiantes, de tal manera que éstos desarrollen un pensamiento crítico, que analicen las actuales problemáticas provocadas por la pandemia desde diferentes perspectivas y formulen sus propios criterios para traer nuevas soluciones y un desempeño eficaz en cualquier campo y ámbito de la vida (figura 6).

Figura 6. Categorización de habilidades académicas y educativas

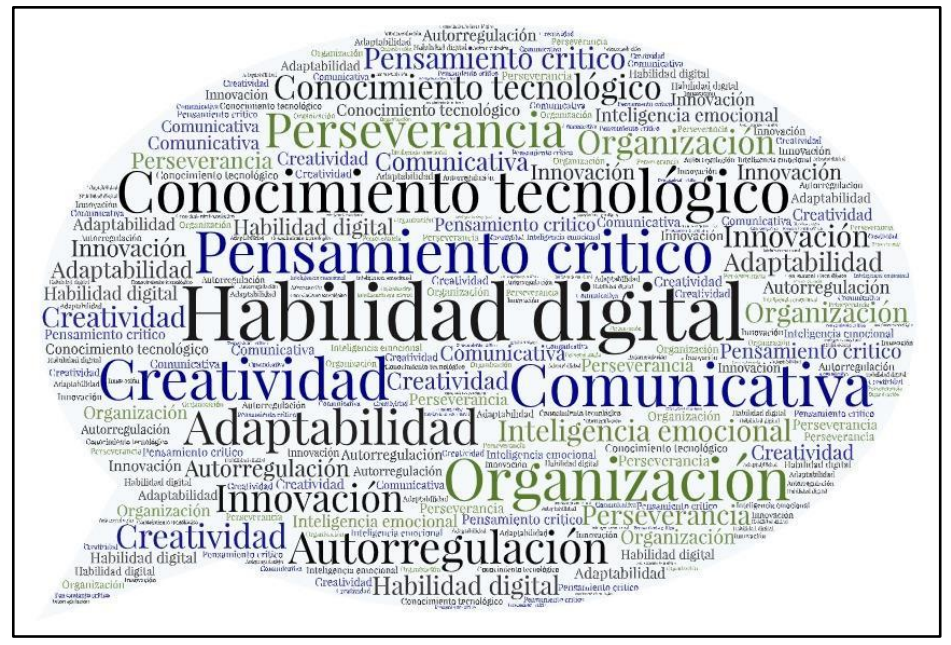

Fuente: Elaboración propia con software ATLAS. ti 


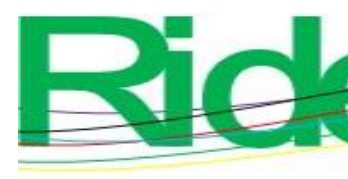

\section{Revista Iberoamericana para la Investigación y el Desarrollo Educativo ISSN 2007 - 7467}

Finalmente, en el quinto taller, "Estrategias para promover con los estudiantes la salud emocional", el objetivo fue identificar acciones para la promoción de la salud emocional, propia y de los estudiantes, y reconocer los efectos causados por la pandemia. Estuvo estructurado a partir de dos cuestionamientos. El primero de ellos fue: “¿Qué afectaciones habrá y cómo va a impactar esto en el plano de enseñanza?”.

En el plano social, los docentes bajo estudio afirmaron que la propagación de la pandemia provocada por el virus de la Covid-19 ha traído consigo una crisis económica, desempleo a nivel global y local, una crisis de salud pública sin precedente que ha causado un enorme sufrimiento y pérdidas de vidas humanas. En el plano educativo, comentaron que las consecuencias en la educación son dramáticas, el sector educativo se ha visto abrumado y que existe una gran presión sobre este sector, por lo que ha afectado negativamente la calidad de la educación.

Por otro lado, se hizo evidente la desigualdad social. Los docentes enfatizaron que se observó una gran desigualdad social debido a que no todos los estudiantes, y los propios profesores contaban con una computadora e internet o banda ancha para continuar su aprendizaje; en consecuencia, los estudiantes que no contaban con equipo tecnológico se quedaron sin acceso a las plataformas virtuales, y el cerrar la escuela provocó una gran deserción de estudiantes a quienes no les fue posible darles continuidad a sus clases.

Además, han planteado la urgente necesidad de realizar cambios en sus estrategias pedagógicas. La mayoría coincidió sobre la urgencia de mejorar las dimensiones cognitivas, sociales, emocionales y conductuales de su aprendizaje, de tal manera que les permita llegar a los estudiantes con mayor facilidad y que éstos, a su vez, aprovechen mejor las clases y los contenidos de las asignaturas correspondientes.

Han reconocido la necesidad de una reestructuración en los programas de estudio, que aborden contenidos y resultados de aprendizaje acorde a las propias experiencias que se han vivido por la pandemia. Los participantes coincidieron sobre la importancia de una nueva pedagogía, una educación integral y transformadora, donde los contenidos abarquen aprendizajes integradores en ambientes y entornos propicios para el aprendizaje.

Coincidieron sobre la importancia de fomentar la conciencia y promover un cambio de conducta ante los sucesos provocados por la pandemia que les permita intensificar los cuidados en sus actividades de limpieza y desinfección, así como mejorar las prácticas de gestión de residuos entre la comunidad educativa con la finalidad de disminuir los riesgos de contagio. 


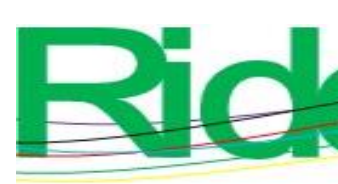

Revista Iberoamericana para la
Investigación y el Desarrollo Educativo
ISSN $2007-7467$

El segundo cuestionamiento de este taller fue: "Para favorecer una práctica profesional sana, ¿qué acciones serán las prioritarias en mi labor docente en la nueva normalidad?".

El profesorado coincidió que la reapertura de las escuelas traerá ciertamente beneficios en todos los sentidos, tanto para los estudiantes como para la economía en general, sin embargo, también reconocieron que es fundamental proteger a los docentes y al personal administrativo, así como a los estudiantes que, de igual manera, corren un alto riesgo de contagio debido a su edad o condiciones de salud, lo que los convierte en propensos y vulnerables ante la pandemia.

Los docentes concluyeron sobre la importancia de desarrollar protocolos claros sobre las medidas de seguridad ante un inminente regreso a las aulas, como primer lugar, de distanciamiento físico, debiendo prohibirse actividades que requieran grandes concentraciones, escalonar el inicio y la terminación de la jornada laboral, trasladar las clases a sitios al aire libre e impartir enseñanza por turnos para reducir los tamaños de los grupos de estudiantes.

El profesorado bajo estudio coincidió sobre la importancia de contar con procedimientos eficaces en las instalaciones de la escuela y una constante comunicación con las autoridades sanitarias para el monitoreo y control de la salud de estudiantes y del personal, la actualización o creación de planes de emergencia para dar seguimiento a los casos vulnerables o infectados, así como los protocolos recomendados por la Secretaría de Salud en cuanto a tomar la temperatura, someter a pruebas a los docentes antes de reabrir las instalaciones escolares para la nueva normalidad, entrenar al personal de limpieza en prácticas de desinfección y dotarlos de equipo de protección personal en la medida de lo posible.

De esta manera, los docentes confirmaron sus temores ante un posible regreso a las aulas presenciales. Argumentaron que en los planteles que laboran no existen las condiciones sanitarias, tecnológicas y técnicas para un regreso seguro para la comunidad educativa. Además, no cuentan con los recursos tecnológicos para migrar a clases híbridas, tal como lo está proponiendo la Secretaría de Educación Pública.

De acuerdo con el análisis de los resultados, se acepta la hipótesis de investigación planteada en un inicio: los aspectos de presión, estrés y ansiedad detectados en el profesorado afectaron significativamente su estado emocional y, en consecuencia, su rendimiento laboral. 


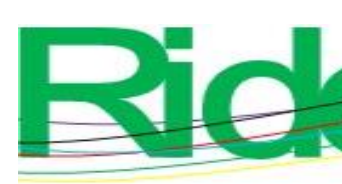

Revista Iberoamericana para la Investigación y el Desarrollo Educativo ISSN 2007-7467

Asimismo, se identificaron fortalezas que les permitieron ser resilientes para continuar con su práctica docente.

\section{Discusión}

Dentro de un contexto complejo y desafiante en el que se encuentra la humanidad a nivel global, los docentes han sido actores fundamentales en la respuesta a la pandemia de Covid-19: han respondido a una serie de demandas emergentes durante la crisis sociosanitaria, lo que ha traído un desequilibrio en todos los ámbitos del docente e impactos socioemocionales importantes, tal como se muestra en los resultados de la presente investigación. En el estudio de Tacca y Tacca (2019), al igual que aquí, se detectó que los principales síntomas de estrés han sido el cansancio, falta de sueño, dolor de cabeza, falta de concentración, desequilibrio en los hábitos alimenticios, entre otros; todos ellos hablan de los impactos socioemocionales que representa el ser docente. Aunado a lo anterior, y con base en los resultados de esta investigación, se puede afirmar que los grados de estrés van en aumento. Sin duda los efectos de la pandemia han profundizado aún más los impactos socioemocionales.

Organismos internacionales como la Unesco (2020) han hecho hincapié sobre los efectos provocados por la actual pandemia del coronavirus, la que ha causado el cierre de los centros educativos, la necesidad del distanciamiento físico, la pérdida de seres queridos, del trabajo y el cambio de los métodos de aprendizaje tradicionales, han generado estrés, presión y ansiedad a docentes, estudiantes y sus familias, lo que ha resultado agotador y desgastante. La salud física y emocional de los docentes sin duda se ha visto afectada y en algunos casos seriamente comprometida.

Los ya citados Garrick et al. (2014), Jensen et al. (2012) y Skaalvik y Shaalvik (2015) dieron cuenta de la existencia de altos índices de insatisfacción, estrés, agotamiento y depresión presentados por docentes en función. Y Alves et al. (2020) encontraron que la pandemia ha reducido la percepción de bienestar entre los docentes y ha puesto en duda su futuro profesional. Estos hallazgos coinciden con los resultados del presente estudio, ya que los docentes bajo estudio manifestaron baja satisfacción en cuanto al reconocimiento tanto económico como profesional de su trabajo docente. En tanto, Lozano (2020) afirma que el trabajo docente genera estrés, incertidumbre y miedo, todo un impacto psicológico negativo, sobre todo en la población más vulnerable. Por otra parte, Morales (2021) determinó en estudiantes universitarios una relación entre el miedo, estrés, resistencia, autoestima y 


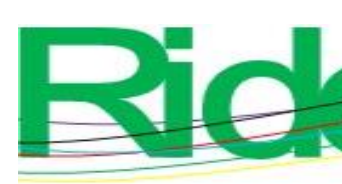

Revista Iberoamericana para la Investigación y el Desarrollo Educativo ISSN $2007-7467$

estrategias de afrontamiento ante la pandemia de la Covid-19, tal como se ha registrado en este estudio, donde los docentes manifestaron tener un alto grado de estrés producto del proceso que están viviendo debido a la pandemia.

Si bien es cierto que el trabajo docente es considerado como una profesión de alto impacto social, quienes lo practican lo consideran como un trabajo agotador y desgastante debido a la gran cantidad de actividades académicas que deben realizar antes y después de una clase frente a grupo. Al respecto, Sanz et al. (2002) afirman que la docencia es considerada como la ocupación que presenta el mayor riesgo de angustia psicológica con los niveles más bajos de satisfacción laboral en comparación con la población en general; así mismo, los docentes han manifestado que el traslado de la educación al plano virtual, ha afectado su salud física y emocional, coincidiendo con López y Pérez (2020) quienes aseveran que la docencia es una de las profesiones que más intensamente ponen el peligro la salud y el bienestar de quienes la ejercen.

En el contexto provocado por la pandemia, los docentes afirmaron que han potenciado su creatividad en el diseño de clases virtuales. Para ello, contar con las competencias digitales necesarias, tener pericia en el manejo de plataformas y herramientas virtuales ha sido invaluable. Eso sí, el tiempo que utilizan para la planeación y elaboración de su trabajo conlleva un sin número de actividades que pueden ser extremadamente estresantes y muchas veces poco valoradas. Al respecto, Aguaded y Almeida (2016) han documentado que la forma en que cada persona responde a las adversidades de la vida y a las experiencias influye en el desarrollo personal, lo que es considerada como una competencia fundamental de todo profesional de la educación.

Martínez, Yániz y Villardón (2017) afirman que los docentes se encuentran sometidos a una serie de desafíos sociales que les exigen más preparación profesional y adaptación, por lo que es necesario contar con un amplio elenco de competencias profesionales para afrontar adecuadamente los retos que les exige el desempeño de su tarea, competencias que sin duda los docentes bajo estudio han afirmado que son necesarias para afrontar los desafíos de su trabajo como docente ante la nueva virtualidad.

La Unesco (2020) ha reconocido que durante la pandemia el profesorado y el personal educativo ha enfrentado las demandas de apoyo socioemocional y de salud mental tanto de los estudiantes como de sus familias, de tal manera que la angustia y ansiedad que mencionan tener los profesores bajo estudio puede estar provocada tanto por los riesgos de salud conexos 


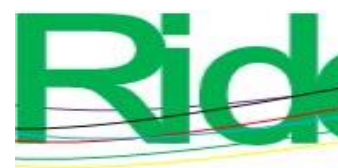

Revista Iberoamericana para la
Investigación y el Desarrollo Educativo
ISSN $2007-7467$

como por el aumento de la carga de trabajo que supone enseñar utilizando métodos nuevos y complejos sin haber recibido una capacitación adecuada.

Finalmente, es necesario poner énfasis en las problemáticas que actualmente padece el profesorado tanto de manera personal como de manera profesional. Si bien es cierto lo que afirma el Ministerio de Educación de Perú (2020) respecto a que el bienestar socioemocional afecta el qué y cómo se aprende, no ha sido fácil para los docentes desarrollar actividades académicas con un formato virtual, ajustar nuevas metodologías, así como la reorganización curricular, el diseño de materiales y diversificación de los medios, formatos y plataformas de trabajo. Tal y como afirman López y Pérez (2020), la educación requiere de una gran cantidad de habilidades técnicas, tecnológicas, académicas y, sobre todo, de una gran implicación emocional con el alumnado, familias y compañeros de trabajo.

El profesorado bajo estudio ha señalado la importancia que tiene la tolerancia y la flexibilidad, la apertura y el trabajo colaborativo. En esa línea, Richardson y Mishra (2018) afirman que estas condiciones facilitan el desarrollo de la enseñanza creativa. Y Díaz (2020) señaló que en el contexto de la pandemia se han generado estrategias de enseñanza mediadas por tecnologías de manera improvisada pero resiliente.

Con base en los resultados obtenidos, se encontró que las docentes registraron un mayor impacto psicológico, ya que, además de factores como el estrés, la ansiedad y la depresión, aunados a las actividades extracurriculares como los diversos cursos promovidos por la propia institución y la SEP, hay que sumar las agobiantes labores de casa producto de los estereotipos de género. De acuerdo con Lozano (2020) y Gervacio y Castillo (2020, 2021), bajo este escenario, de no contar con una intervención inmediata y pertinente, los niveles de estrés, temor, confusión, ira, frustración, preocupación, aburrimiento, soledad, estigma, ansiedad, desesperanza, culpa y depresión se dispararían todavía más, incluso en algunos casos se estaría hablando de suicidio. 


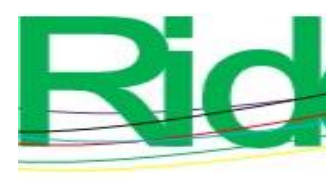

Revista Iberoamericana para la Investigación y el Desarrollo Educativo ISSN 2007 - 7467

\section{Conclusiones}

El trabajo docente en tiempos de pandemia ha sido fundamental para el desarrollo y continuidad académica, para dar atención a distancia y de manera virtual a los grupos de estudiantes que han quedado sin la posibilidad de asistir a clases presenciales debido a la pandemia. Los docentes, al igual que sus propios estudiantes, han buscado los medios más adecuados para mantenerse en contacto, para mantener una comunicación constante, y dar continuidad a las clases a través de diferentes medios de comunicación. Este reto no ha sido fácil, debido a las múltiples complicaciones técnicas, tecnológicas y de comunicación que se presentaron en su momento.

La transformación forzada a partir del traslado a las aulas virtuales ha generado nuevos espacios educativos y ha potenciado la creatividad, ha desarrollado fortalezas resilientes y demostrado una gran capacidad de trabajo y de adaptación para potenciar la enseñanza y los aprendizajes en el profesorado. Las experiencias de los docentes dan cuenta de procesos creativos, la búsqueda de alternativas, el diseño de nuevas estrategias pedagógicas, donde el principal interés son las necesidades e intereses de los estudiantes y las condiciones de sus familias.

En este sentido, los docentes no solo están construyendo aprendizajes, sino que también han creado vínculos afectivos, socioemociones y empatía con los estudiantes y sus familias, han aprendido sobre la importancia que tiene la tolerancia y la flexibilidad, la apertura y el trabajo colaborativo. Ahora parece ser que el siguiente paso será adaptarse a modelos pedagógicos mixtos, blended learning o híbridos, los cuales demandan incorporar formas de enseñanza multimedia basada en las TIC, de tal manera que no solo el profesorado deberá continuar capacitándose para hacer frente a este nuevo reto educativo, sino que las instituciones deberán equiparse con lo necesario para llevar a cabo esta nueva modalidad de enseñanza y aprendizaje.

Por otro lado, los docentes, como profesionales de la educación, han permanecido expuestos a los impactos provocados por la actual pandemia del coronavirus (Covid-19), han estado en constante riesgos de contagio, se ha visto afectada su salud física y emocional, han tenido que lidiar con las emociones que les ha provocado el estrés. En efecto, como se documentó en los resultados, se ha afectado su tranquilidad, paz, calma y sentido del humor, lo que ha traído consecuencias en su contexto inmediato y sus relaciones intrafamiliares, su entorno, su economía y su rendimiento laboral. 


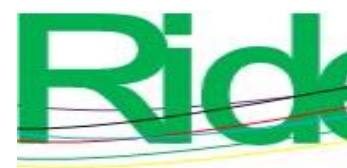

Revista Iberoamericana para la
Investigación y el Desarrollo Educativo
ISSN $2007-7467$

Centro de Investigación de la Universidad La Salle, 14(53), 45-66. Recuperado de https://doi.org/10.26457/recein.v14i53.2658.

Gervacio, H. y Castillo, B. (2021) Impactos de la pandemia Covid-19 en el rendimiento escolar durante la transición a la educación virtual. Revista Pedagógica, 23, 1-29. Recuperado de https://doi.org/10.22196/rp.v22i0.6153.

Habermas, J. (2018). Teoría de la acción comunicativa: Tomo I. Racionalidad de la acción y racionalización social. Madrid, España: Trotta.

Hernández, R. y Mendoza, C. (2018). Metodología de la Investigación. Las rutas cuantitativa, cualitativa y mixta, Ciudad de México, México: McGraw-Hill Education.

Hernández, R., Fernández, C. y Baptista, P. (2014). Metodología de la investigación (6. a ed.) Ciudad de México, México: McGraw-Hill.

Jensen, B., Sandoval, A., Knoll, S. and González, E. J. (2012). The Experience of New Teachers: Results from TALIS 2008. Paris, France: Organisation for Economic Co$\begin{array}{llll}\text { operation and } \quad \text { Development. } & \text { Retrieved }\end{array}$ https://doi.org/10.1787/9789264120952-en.

López, È. y Pérez, N. (2020). La influencia de las emociones en la educación ante la COVID19. El caso de España desde la percepción del profesorado. Barcelona, España: Universitat de Barcelona. Recuperado de http://diposit.ub.edu/dspace/bitstream/2445/173449/4/2020_Informe_La\%20influen cia\%20de\%20las\%20emociones\%20en\%20la\%20educaci\%c3\%b3n\%20ante\%201a \%20COVID-19.pdf.

Lozano, A. (2020). Impacto de la epidemia del coronavirus (COVID-19) en la salud mental del personal de salud y en la población general de China. Revista de NeuroPsiquiatría, 83(1), 51-56. Recuperado de https://dx.doi.org/10.20453/rnp.v83i1.3687.

Martínez, M., Yániz, C. y Villardón, L. (2017). Competencias profesionales del profesorado de educación obligatoria. Revista Iberoamericana de Educación, 74(1), 171-192. Recuperado de https://doi.org/10.35362/rie740613.

Ministerio de Educación. (1 de abril de 2020). Resolución Ministerial N016-2020MINEDU. $\quad E l \quad$ Peruano, $\quad$ pp. https://cdn.www.gob.pe/uploads/document/file/574684/disponen-el-inicio-del-ano- 


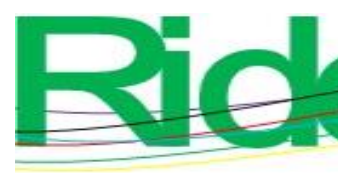

Revista Iberoamericana para la
Investigación y el Desarrollo Educativo
ISSN $2007-7467$

escolar-a-traves-de-la-implementa-resolucion-ministerial-n-160-2020-minedu1865282-1.pdf.

Morales, F. M. (2021). Fear, Stress, Resilience and Coping Strategies during COVID-19 in Spanish University Students. Sustainability, 13(11), 1-19. Retrieved from https://doi.org/10.3390/su13115824.

Organización de las Naciones Unidas para la Educación, la Ciencia y la Cultura [Unesco]. (2016). Sistematización de experiencias educativas innovadoras. (1. ${ }^{\mathrm{a}}$ ed.), Lima, Perú: Organización de las Naciones Unidas para la Educación, la Ciencia y la Cultura. Recuperado de https://unesdoc.unesco.org/ark:/48223/pf0000247007.

Organización de las Naciones Unidas para la Educación, la Ciencia y la Cultura [Unesco]. (2020). Respuesta del ámbito educativo de la Unesco al COVID-19. Nota temática núm. 1-2. Recuperado de https://unesdoc.unesco.org/ark:/48223/pf0000373271_spa. Organización de las Naciones Unidas para la Educación, la Ciencia y la Cultura [Unesco]Instituto Internacional para la Educación Superior en América Latina y el Caribe [Iesalc]. (2020). COVID-19 y educación superior: de los efectos inmediatos al día después. Análisis de impactos, respuestas políticas y recomendaciones. Recuperado de https://www.iesalc.unesco.org/wp-content/uploads/2020/05/COVID-19-ES130520.pdf.

Pérez, N. y Filella, G. (2019). Educación emocional para el desarrollo de competencias emocionales en niños y adolescentes. Revista Praxis \& Saber, 10(24), 23-44. Recuperado de https://doi.org/10.19053/22160159.v10.n25.2019.8941.

Pérez, G. (2008). La educación como respuesta a los retos que plantea la escuela. Bordón. Revista de Pedagogía, 60(4),15-29.

Pértigas, S. y Pita, S. (2002). Determinación del tamaño muestral para calcular la significación del coeficiente de correlación lineal. Cuadernos de Atención Primaria, 9(4), 209-211. Recuperado de https://www.fisterra.com/mbe/investiga/pearson/pearson2.pdf.

Rekalde, I., Vizcarra, M. T. y Makazaga, A. M. (2011). La aventura de investigar. Una experiencia de investigación acción participativa. Aula Abierta, 39(1), 93-104. Recuperado de http://www.uniovi.net/ICE/publicaciones/Aula_Abierta/numeros_anteriores_hasta_ 2013/i15/11_AulaAbierta_Vol39_n1_enero_2011. 


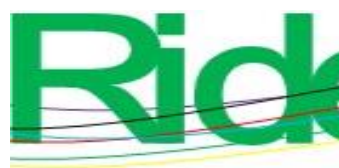

Revista Iberoamericana para la
Investigación y el Desarrollo Educativo
ISSN $2007-7467$

Rekalde, I., Vizcarra, M. T. y Macazaga, A. M. (2014). La observación como estrategia de investigación para construir contextos de aprendizaje y fomentar procesos participativos. Educación XX1, 17(1), 201-220. Recuperado de https://redalyc.org/pdf/706/70629509009.pdf.

Richardson, C. and Mishra P. (2018). Learning environments that support student creativity: Developing the SCALE. Thinking Skills and Creativity, 27, 45-54. Retrieved from https://doi.org/10.1016/j.tsc.2017.11.004.

Robinet, A. L. y Pérez, M. (2020). Estrés en los docentes en tiempos de pandemia covid19. Polo del Conocimiento, 5(12), 637-653. Recuperado de https://polodelconocimiento.com/ojs/index.php/es/article/view/2111/4197.

Sanz, C., García, J., Rubio, A., Santed, M. A. and Montoro, M. (2002). Validation of the Spanish version of the Perceived Stress Questionnaire. Journal of Psychosomatic Research 52(3), 167-172. Retrieved from https://doi.org/10.1016/S00223999(01)00275-6.

Secretaría de Educación Pública [SEP]. (2020). Orientaciones pedagógicas para el inicio y organización del ciclo escolar 2020-2021. Guía para el trabajo docente. México: Secretaría de Educación Pública. Recuperado de https://bibliospd.files.wordpress.com/2020/07/anexo-2-guc3ada-pedagc3b3gicaresumen-cte.pdf.

Sierra, R. (2001). Técnicas de investigación social. Teoría y ejercicios (14. ${ }^{\mathrm{a}}$ ed.) Madrid, España: Paraninfo-Thomson Learning.

Skaalvik, E. M. and Skaalvik, S. (2015). Job Satisfaction, Stress and Coping Strategies in the Teaching Profession-What Do Teachers Say? International Education Studies, 8(3), 181-192. Retrieved from https://doi.org/10.5539/ies.v8n3p181.

Tacca, D. R. y Tacca, A. L. (2019). Factores de riesgos psicosociales y estrés percibido en docentes universitarios. Propósitos y Representaciones, 7(3), 323-353. Recuperado de http://dx.doi.org/10.20511/pyr2019.v7n3.304.

Varguillas, C. (2006). El uso de Atlas.ti y la creatividad del investigador en el análisis cualitativo de contenido UPEL. Laurus, 12, 73-87. Recuperado de https://www.redalyc.org/articulo.oa?id=76109905 


\begin{tabular}{|c|c|}
\hline Rol de Contribución & Autor (es) \\
\hline Conceptualización & Herlinda Gervacio Jiménez (Principal) \\
\hline Metodología & $\begin{array}{l}\text { Herlinda Gervacio Jiménez (igual), Benjamín Castillo Elías } \\
\text { (igual) }\end{array}$ \\
\hline Software & Herlinda Gervacio Jiménez (Principal) \\
\hline Validación & $\begin{array}{l}\text { Herlinda Gervacio Jiménez (igual), Benjamín Castillo Elías } \\
\text { (igual) }\end{array}$ \\
\hline Análisis Formal & $\begin{array}{l}\text { Herlinda Gervacio Jiménez (igual), Benjamín Castillo Elías } \\
\text { (igual) }\end{array}$ \\
\hline Investigación & Herlinda Gervacio Jiménez (Principal) \\
\hline Recursos & $\begin{array}{l}\text { Herlinda Gervacio Jiménez (igual), Benjamín Castillo Elías } \\
\text { (igual) }\end{array}$ \\
\hline Curación de datos & $\begin{array}{l}\text { Herlinda Gervacio Jiménez (Principal), Benjamín Castillo Elías } \\
\text { (que apoya) }\end{array}$ \\
\hline $\begin{array}{l}\text { Escritura - Preparación del } \\
\text { borrador original }\end{array}$ & $\begin{array}{l}\text { Herlinda Gervacio Jiménez (igual), Benjamín Castillo Elías } \\
\text { (igual) }\end{array}$ \\
\hline $\begin{array}{l}\text { Escritura - Revisión y } \\
\text { edición }\end{array}$ & $\begin{array}{l}\text { Herlinda Gervacio Jiménez (igual), Benjamín Castillo Elías } \\
\text { (igual) }\end{array}$ \\
\hline Visualización & $\begin{array}{l}\text { Herlinda Gervacio Jiménez (igual), Benjamín Castillo Elías } \\
\text { (igual) }\end{array}$ \\
\hline Supervisión & $\begin{array}{l}\text { Herlinda Gervacio Jiménez (igual), Benjamín Castillo Elías } \\
\text { (igual) }\end{array}$ \\
\hline Administración de Proyectos & $\begin{array}{l}\text { Herlinda Gervacio Jiménez (igual), Benjamín Castillo Elías } \\
\text { (igual) }\end{array}$ \\
\hline Adquisición de fondos & $\begin{array}{l}\text { Herlinda Gervacio Jiménez (igual), Benjamín Castillo Elías } \\
\text { (igual) }\end{array}$ \\
\hline
\end{tabular}

